\title{
Evaluation of postural balance in patients with obstructive sleep apnoea syndrome
}

\author{
Turgay Demir ${ }^{1}$, Kezban Aslan ${ }^{2}$, Meltem Demirkiran ${ }^{3}$ \\ ${ }^{1}$ Cukurova University, School of Medicine, Department of Neurology, Adana, Turkey \\ ${ }^{2}$ Cukurova University, School of Medicine, Sleep Disorders Unit, Department of Neurology, Adana, Turkey \\ ${ }^{3}$ Cukurova University, School of Medicine, Movement Disorders Unit, Department of Neurology, Adana, Turkey
}

\begin{abstract}
Introduction. Patients with obstructive sleep apnoea syndrome (OSAS) can be more prone to accidents due to excessive daytime sleepiness which can lead to attention deficits and thereby cause balance problems. One of the tests evaluating postural balance is static posturography (SPG). In this study, we aimed to evaluate postural balance with SPG in OSAS patients.

Methods. Patients who were referred to a sleep disorders outpatient clinic of a tertiary health care centre with snoring, daytime sleepiness or witnessed apnoea were enrolled consecutively in this cross-sectional study. They were grouped as the OSAS group and the control group according to the apnoea-hypopnoea index. Posturographic analyses were carried out in all subjects on a SPG platform under five different conditions: eyes open (EO), eyes closed (EC), head rotated to left (HL), head rotated to right $(\mathrm{HR})$, and tandem Romberg.
\end{abstract}

Results. A total of 95 patients and 23 controls were included in the study. In EO conditions, there was no difference between the OSAS group and the control group in any of the posturographic parameters. In EC conditions, change in lateral sway was significantly higher in the OSAS group which also correlated negatively with $\mathrm{SaO}_{2(\mathrm{~min})}$. $\mathrm{HR}$ conditions caused an increase in anterior-posterior (A-P) sway velocity, and HL conditions led to an increase in change in lateral and A-P sways, sway area, and sway area velocity in the OSAS group.

Conclusions. Our findings suggest that postural balance in OSAS patients is impaired even in the very first hours of the day, and that the severity of the disease has an impact on postural balance.

Key words: balance, obstructive sleep apnoea, static posturography, postural stability

(Neurol Neurochir Pol 2020; 54 (1): 83-89)

\section{Introduction}

Obstructive sleep apnoea (OSA) is a disease characterised by recurrent, complete, or partial obstruction of the upper respiratory tract. OSA when associated with excessive daytime sleepiness is commonly called obstructive sleep apnoea syndrome (OSAS). Its main symptoms are snoring, witnessed apnoea, and excessive daytime sleepiness [1]. Heinze et al. reported the prevalence of moderate-to-severe (apnoea-hypopnoea index of 15 or more events per hour) sleep-disordered breathing in men to be $49.7 \%$ and in women $23.7 \%$ [2]. Peppard et al. reported the prevalence of moderate-to-severe sleep-disordered breathing in relation to age and gender to be $10 \%$ in men aged $30-49,17 \%$ in men aged $50-70,3 \%$ in women aged $30-49$, and $9 \%$ in women aged 50-70 [3].

In OSAS, hypoxia-related sleep fragmentation affects the cardiovascular system, the central nervous system, cognitive functions, executive functions, attention, and motor coordination [4]. Excessive daytime sleepiness, which is common in OSAS, causes loss of attention and balance [5]. Moreover, excessive daytime sleepiness, which can affect psychomotor performance as much as alcohol, causes an increase in the incidence of traffic accidents and impaired work performance [6].

Address for correspondence: Turgay Demir, Cukurova University, School of Medicine, Department of Neurology Adana, 01330, Turkey, e-mail: drtdemir@gmail.com 
Balance is achieved through the integration of vestibular, visual, and proprioceptive information in the central nervous system [7]. According to several studies using a sleep deprivation model, the vestibular system is affected by an increase in the length of awakening time $[8,9]$. In addition, it has been reported that sleep deprivation causes changes in the posterior parietal cortex in humans, and this region is also important in processing vestibular inputs and controlling vestibulocular reflex $[10,11]$. Sleep deprivation and poor-quality sleep in OSAS patients may also affect postural control.

Posturography, also known as a balance test, allows the evaluation of postural stability on static and dynamic platforms. The basic principle of static posturography (SPG) is the measurement of changes in centre of foot pressure on a stationary platform [12]. SPG helps to assess the effects of visual, vestibular, and somatosensory inputs on postural control effectively [9].

In this study, we aimed to investigate the effects of OSAS on postural stability through SPG, and to evaluate the relationship between disease level and SPG values.

\section{Methods}

\section{Participants}

This prospective cross-sectional comparative study was carried out in the Sleep Centre at the, Department of Neurology, Cukurova University. Patients referred to the outpatient clinic for snoring, daytime sleepiness, and probable apnoea over a 12 month period were consecutively enrolled in the study. Patients with sedative drug use, neurological disorders which can affect posture and balance (Parkinson's disease, dystonia, chorea, multiple sclerosis, cerebrovascular disease, ataxia, polyneuropathy etc.), rheumatological or orthopedic disease, mental retardation, dementia, vestibular or otological disease, severely blurred vision and a history of substance abuse were excluded. Informed consent was obtained from all subjects. The University Ethics Committee of the Faculty approved the study.

Clinical features including age, gender, body mass index (BMI), and past medical history regarding hypertension (HT), diabetes mellitus (DM), hyperlipidemia, atherosclerotic heart disease (ASHD), pulmonary disease, thyroid disease, stroke history, alcohol use, and smoking were recorded. Measurements of the neck, chest, and waist circumferences were performed for all subjects. Patients were divided into two groups designated as the control group and the OSAS group. The control group consisted of subjects with an apnoea-hypopnoea index (AHI) $<5 /$ hour, and the OSAS group consisted of subjects with an AHI $>5 /$ hour. All patients received an SPG test. Patients with OSAS also had a polysomnographic (PSG) evaluation.

\section{Procedures Sleep Study}

A full-night PSG was performed using a computerised system (Kommet, Grass telefactor) and the following parameters were recorded: electrooculogram (2 channels), electroencephalogram (6 channels), submental muscle electromyogram (2 channels), anterior tibial muscle electromyogram for both legs ( 2 channels), electrocardiogram (1 channel), airflow (oronasal pressure adjusted cannula), chest and abdominal movements respiratory inductance plethysmography (2 channels), and arterial oxyhaemoglobin saturation with finger-probe pulse oximetry $\left(\mathrm{SaO}_{2}: 1\right.$ channel).

Records were taken at a $10 \mathrm{~mm} / \mathrm{s}$ sweep rate. Sleep stages were scored according to the American Academy of Sleep Medicine (AASM) 2007 standard criteria [13]. Apnoea was defined as complete cessation, or a drop in the peak signal excursion by $\geq 90 \%$, of the pre-event baseline of airflow $\geq 10 \mathrm{~s}$. Hypopnoea was considered as a peak signal excursions drop by $\geq 30 \%$ of the pre-event baseline of the airflow $\geq 10 \mathrm{~s}$, and a $\geq 3 \%$ oxygen desaturation from pre-event baseline or an event associated with awakening. Leg movements were evaluated in accordance with AASM recommendations (AASM, 2005). Leg movements causing an increase of at least $8 \mu \mathrm{V}$ in resting EMG activity in a $0.5-10$ s period were counted. Sequential $\geq 4$ movements for a total of 5-90 seconds were accepted as periodic limb movement (PLM).

The Epworth Sleepiness Scale (ESS) is an eight-item self-reported measure of daytime sleepiness [14]. Respondents indicate on a four-point Likert-type scale $(0=$ never, $4=$ high chance) the likelihood of dozing off in eight different situations. The responses are totalled to yield a score of between 0 and 24, with higher scores indicating greater sleepiness. Turkish validity and reliability analyses of the ESS were performed yielding a Cronbach alpha $\geq 0.86$ indicating good reliability [15].

\section{Posturography protocol}

SPG examinations were performed between $7 \mathrm{am}$ and $8 \mathrm{am}$, at least 30 minutes after the PSG study had been completed, so that patients acknowledged that they were fully awake. SPG was performed on a force platform (Lucerne II) in a quiet room. The subjects were told to stand on the platform in an upright position as stably as possible, barefoot, with their feet $4 \mathrm{~cm}$ apart, and their arms held alongside their body. The first recording was with eyes open (EO), the second with eyes closed (EC), the third with head rotated to the right and eyes closed (HR), the fourth with head rotated to the left and eyes closed (HL), and the fifth and last with tandem stance eyes closed (TAN). In the tandem stance, one foot is in front of the other, and arms are lifted horizontally in front of the body. Each test lasted 30 seconds. Anteroposterior sway, lateral sway, total body sway, sway area, as well as the velocity of all of these sway values (anteroposterior sway/time, lateral sway/ time, total body sway/time, sway area/time) were recorded. SPG parameters are set out in Table 1.

\section{Statistical analysis}

All analyses were performed using IBM ${ }^{\circ}$ SPSS for Windows software (Version 20.0. IBM Corp., Armonk, NY, USA). Categorical variables were expressed as numbers and 
Table 1. Definition of static posturography parameters

\begin{tabular}{|c|c|}
\hline Parameter & Definition \\
\hline Way & $\begin{array}{l}\text { Sum of movements of centre of pressure during whole } \\
\text { examination time }(\mathrm{cm})\end{array}$ \\
\hline Way/t & $\begin{array}{l}\text { Average speed of movement of centre of pressure } \\
(\mathrm{cm} / \mathrm{sec}) \text { (way velocity) }\end{array}$ \\
\hline \multirow[t]{4}{*}{$\begin{array}{l}\text { Sway Area } \\
\text { (SA) }\end{array}$} & $\begin{array}{l}\text { Calculation of sway area acording to formula of Die- } \\
\text { ner/Dichgans/Bacher }\left(\mathrm{cm}^{2}\right) \text {; xi and yi are coordinates } \\
\text { at time i of centre of pressure) }\end{array}$ \\
\hline & $n-1$ \\
\hline & $S A=1 / 2 \sum\left|x_{i+1} y_{i+1} x_{i}\right|$ \\
\hline & $i=1$ \\
\hline $\mathrm{SA} / \mathrm{t}$ & Area divided by time $\left(\mathrm{cm}^{2} / \mathrm{sec}\right)$ (sway area velocity) \\
\hline Dx & $\begin{array}{l}\text { Maximum lateral sway difference, i.e. max elongation } \\
\text { in } \pm x \text { direction }(\mathrm{cm})\end{array}$ \\
\hline Dy & $\begin{array}{l}\text { Maximum anterior/posterior sway difference i.e. } \\
\text { elongation in } \pm \text { y direction }(\mathrm{cm})\end{array}$ \\
\hline $\begin{array}{l}\text { Anterior- } \\
\text {-posterior }\end{array}$ & $\begin{array}{l}\text { Sum of y components of movement vectors }(\mathrm{cm} / \mathrm{s}) \\
\qquad \sum\left|y_{i+1}-y_{i}\right|\end{array}$ \\
\hline $\begin{array}{l}\text { Anterior- } \\
\text {-posterior/t }\end{array}$ & $\begin{array}{l}\text { Quotient of antero-posterior ant time }(\mathrm{cm} / \mathrm{s}) \text { (anterior- } \\
\text {-posterior sway velocity) }\end{array}$ \\
\hline Lateral & $\begin{array}{l}\text { Sum of x components of movement vectors }(\mathrm{cm}) \\
\qquad \sum\left|y_{\mathrm{i}+1}-y_{\mathrm{i}}\right|\end{array}$ \\
\hline Lateral/t & $\begin{array}{l}\text { Quotient of lateral and time }(\mathrm{cm} / \mathrm{s}) \text { (lateral sway } \\
\text { velocity) }\end{array}$ \\
\hline
\end{tabular}

percentages, whereas continuous variables were summarised as the mean and the standard deviation and as the median and the minimum-maximum, where appropriate. A chi-square test was used to compare categorical variables between groups. The normality of distribution for continuous variables was confirmed with the Shapiro-Wilk test. For comparison of groups, a one-way ANOVA or Kruskal-Wallis test was used depending on whether statistical hypotheses were fulfilled. For normally distributed data, regarding the homogeneity of variances, Scheffe or Tamhane T2 tests were used for multiple comparisons of groups. For data that was not normally distributed, a Bonferroni-adjusted Mann-Whitney U test was used for multiple comparisons of groups.

The patients were divided into two groups: $\mathrm{AHI}<15$ and AHI $>15$. In a logistic regression model, where disease status was considered as a dependent variable, all parameters that had significant differences as a result of binary comparisons were included as independent variables. Binary logistic regression, BACKWARD: LR were used as method. The optimum model was selected and the parameters that make a significant contribution to the model are given in the table. The statistical level of significance for all tests was considered to be 0.05 .

\section{Results}

\section{Participants}

A total of 95 patients and 23 controls were included in the study. There were more male patients in the OSAS group (85.3\% vs $52.2 \%)$ compared to the controls. The mean age of
Table 2. Demographic features and risk factors of OSAS

\begin{tabular}{|c|c|c|c|}
\hline & $\begin{array}{l}\text { Controls } \\
(n=23)\end{array}$ & $\begin{array}{c}\text { OSAS } \\
(n=95)\end{array}$ & p-value \\
\hline \multicolumn{4}{|l|}{ Sex, $\mathrm{n}(\%)$} \\
\hline Male & $12(52.2)$ & $81(85.3)$ & 0.003 \\
\hline *Age (years) & $\begin{array}{l}46.48 \pm 9.49 \\
(31-75)\end{array}$ & $\begin{array}{l}49.56 \pm 10.05 \\
(23-74)\end{array}$ & 0.185 \\
\hline${ }^{*} \mathrm{BMI}$ & $28.55 \pm 4.19$ & $32.89 \pm 6.7$ & 0.001 \\
\hline Hypertension, n (\%) & $8(36.4)$ & $41(44.1)$ & 0.51 \\
\hline DM, n (\%) & $5(22.7)$ & $18(19.4)$ & 0.722 \\
\hline Hyperlipidemia, n (\%) & $4(18.2)$ & $29(31.2)$ & 0.225 \\
\hline ASHD, n (\%) & $2(9.1)$ & $12(12.9)$ & 0.612 \\
\hline Thyroid disease, n (\%) & 0 & $3(3.2)$ & 0.256 \\
\hline Stroke, n (\%) & $2(9.1)$ & $1(4.2)$ & 0.105 \\
\hline Pulmonary disease, n (\%) & 0 & $2(2.2)$ & 0.354 \\
\hline Current smoker, n (\%) & $10(43.5)$ & $50(52.6)$ & 0.921 \\
\hline Alcohol abuse, n (\%) & $2(9.1)$ & $14(15.2)$ & 0.644 \\
\hline${ }^{*}$ Neck circumference $(\mathrm{cm})$ & $37.48 \pm 4.15$ & $41.86 \pm 4.08$ & 0.001 \\
\hline${ }^{*}$ Chest girth $(\mathrm{cm})$ & $104 \pm 8.95$ & $112.39 \pm 11.5$ & 0.001 \\
\hline $\begin{array}{l}\text { *Waist circumference } \\
(\mathrm{cm})\end{array}$ & $98.45 \pm 11.13$ & $112.1 \pm 14.79$ & 0.001 \\
\hline
\end{tabular}

ASHD - atherosclerotic heart disease; $\mathrm{BMI}$ - body mass index; $\mathrm{DM}$ - diabetes mellitus ${ }^{*}$ Mean \pm SD

the OSAS group was $49.56 \pm 10.05$ years, and the mean age of the control group was $46.48 \pm 9.49$ years. There was no significant difference between the OSAS and the control groups regarding HT, DM, hyperlipidemia, ASHD, thyroid disease, pulmonary disease, stroke, active smoking, or alcohol use $(P>0.05)$. Mean neck, chest, and waist circumferences were significantly higher in the OSAS group than in the control group $(P<0.001)$ (Tab. 2).

\section{Polysomnographic findings}

The mean ESS and AHI values were significantly higher in the OSAS group compared to the control group, as well as the N2 and N3 durations. Total REM duration was higher in controls, but did not reach statistical significance. On the other hand, $\mathrm{SaO}_{2(\min )}$ was significantly lower in the OSAS group (Tab. 3).

\section{Posturographic findings}

There was no significant difference between the control and the OSAS groups in the posturographic parameters in EO conditions. In EC conditions, the delta $\mathrm{x}$ value, which shows maximum lateral sway difference, was significantly higher in the OSAS group, but there was no significant difference in the other parameters. In HL conditions, delta $\mathrm{x}$, delta $\mathrm{y}$, sway area and sway area velocity values were significantly higher in the OSAS group (Table 4). In HR conditions, A-P sway and A-P sway velocity and in tandem Romberg way and way velocity were 
Table 3. Polysomnographic findings

$\begin{array}{lccc} & \text { Controls } & \text { OSAS } & \text { P-value } \\ \text { mean } \pm \text { SD } & \text { mean } \pm \text { SD } & 0.018 \\ \text { ESS } & 4.47 \pm 3.5 & 8.36 \pm 5.98 & <0.001 \\ \text { AHI } & 1.88 \pm 1.62 & 40.87 \pm 28.61 & 0.264 \\ \text { Systolic blood pressure }(\mathrm{mmHg}) & 125 \pm 18.02 & 131.56 \pm 25.25 & 0.461 \\ \text { Diastolic blood pressure }(\mathrm{mmHg}) & 78.57 \pm 9.63 & 81.36 \pm 16.57 & 0.318 \\ \text { Total sleep time per night, } \mathrm{min} & 359.18 \pm 46.05 & 370.46 \pm 47.8 & 0.305 \\ \text { Sleep efficiency } & 89.17 \pm 8.88 & 100.51 \pm 51.27 & 0.511 \\ \text { Wake time after sleep onset, } \mathrm{min} & 22.54 \pm 30.24 & 18.32 \pm 26.8 & 0.022 \\ \text { Number of awakenings } & 3.3 \pm 2.22 & 2.11 \pm 2.2 & 0.576 \\ \text { Sleep maintenance } & 93.25 \pm 7.39 & 94.17 \pm 6.95 & 0.346 \\ \text { REM episode } & 3.13 \pm 1.17 & 2.84 \pm 1.33 & 0.077 \\ \text { \% N1 } & 11.05 \pm 7.66 & 8.25 \pm 6.37 & <0.001 \\ \text { \% N2 } & 56.63 \pm 8.15 & 71.01 \pm 12.17 & <0.001 \\ \text { \% N3 } & 3.35 \pm 1.46 & 10.97 \pm 9.88 & 0.141 \\ \text { \% REM } & 11.56 \pm 6.35 & 9.6 \pm 5.51 & 48.18 \pm 9.32 \\ \text { Minimum heart rate (beat/min) } & 47.32 \pm 9.63 & 116.22 \pm 12.42 & 0.698 \\ \text { Maximum heart rate (beat/min) } & 113.64 \pm 13.4 & 72.29 \pm 18.75 & 0.39 \\ \text { SaO2(min) (\%) } & 89.95 \pm 4.78 & <0.001\end{array}$

AHI - apnoea-hypopnoea index; ESS — Epworth sleepiness scale; N1 — stage N1 sleep; N2 - stage N2 sleep; N3 - stage N3 sleep; OSAS - obstructive sleep apnoea syndrome; REM — rapid eye movement; $\mathrm{SaO}_{2(\min )}-$ minimum oxygen saturation; $\mathrm{SD}-$ standard deviation

higher in the OSAS group. Furthermore, in tandem Romberg lateral and A-P sways, and their velocities, had a tendency to be higher in the OSAS group compared to the controls $(\mathrm{P}=0.06)$, but these did not reach statistical significance (Tab. 4).

As a result of logistic regression analysis, EC-delta x parameter was found to have a significant effect in the current model $(\mathrm{p}<0.05)$. Increasing the EC-delta $\mathrm{x}$ parameter by one unit will increase the risk of disease development by 4,337 times $(95 \% \mathrm{CI}=1,516-12,408)$. Neck circumference was found to have a significant effect on the model $(\mathrm{p}<0.05)$. A one-unit increase in the neck circumference parameter will increase the risk of disease development by 1,738-fold ( $95 \%$ CI $=1,239$ $2,437)$. N2 parameter was found to have a significant effect on the model ( $\mathrm{p}<0.05)$. The risk of developing the disease will increase by 1,127 times $(95 \% \mathrm{CI}=1,021-1,243)$ with a one unit increment of $\mathrm{N} 2$ parameter (Tab. 5).

\section{Discussion}

Postural balance is achieved by a combination of visual input, proprioception, and vestibular function [16]. Any coordinated change in any of these systems can adversely affect postural balance [17]. Balance disorders can lead to an increased risk of falls and other serious accidents. Daytime sleepiness and attention deficits are common in OSAS. Distraction may increase the risk of imbalance and falls in these patients. Few studies have evaluated postural stability in OSAS patients.
Our study shows that postural balance in patients with OSAS is affected. It also shows that different conditions have different impacts on posturographic balance in OSAS patients compared to controls. This impairment in balance was more pronounced with eyes closed conditions, especially when the head rotations were added or stance surface was narrowed. Also, logistic regression analyses support this finding, with the risk of the disease developing increasing 4.337 times with EC-delta $\mathrm{x}$ conditions.

This shows that visual input is essential to provide postural balance efficiently during stance in OSAS patients. In line with our study, Howcroft et al. reported that eyes-closed results were significantly greater than eyes-open for almost all SPG parameters [18]. Our study also shows that the impairment in postural balance changes with disease severity. Almost all posturographic parameters in $\mathrm{HL}$, and a few in $\mathrm{HR}$, conditions correlated with AHI. This shows that head rotations seem to have an impact on balance in these patients in relation to the severity of the disease. In accordance with this finding, Kayabasi et al. [19] and Gallina et al. [20] reported that the vestibular system was more affected in moderate-to-severe OSAS than in mild. The severity of AHI does not seem to affect postural balance in eyes-open conditions.

Studies have shown that postural stability is affected by sleep deprivation of 24-48 hours, and that its detrimental effects can disappear over 19 hours [21-24]. Liu et al. also reported that sleep deprivation has a negative effect on postural sway and that this may be due to a reduction in attention 


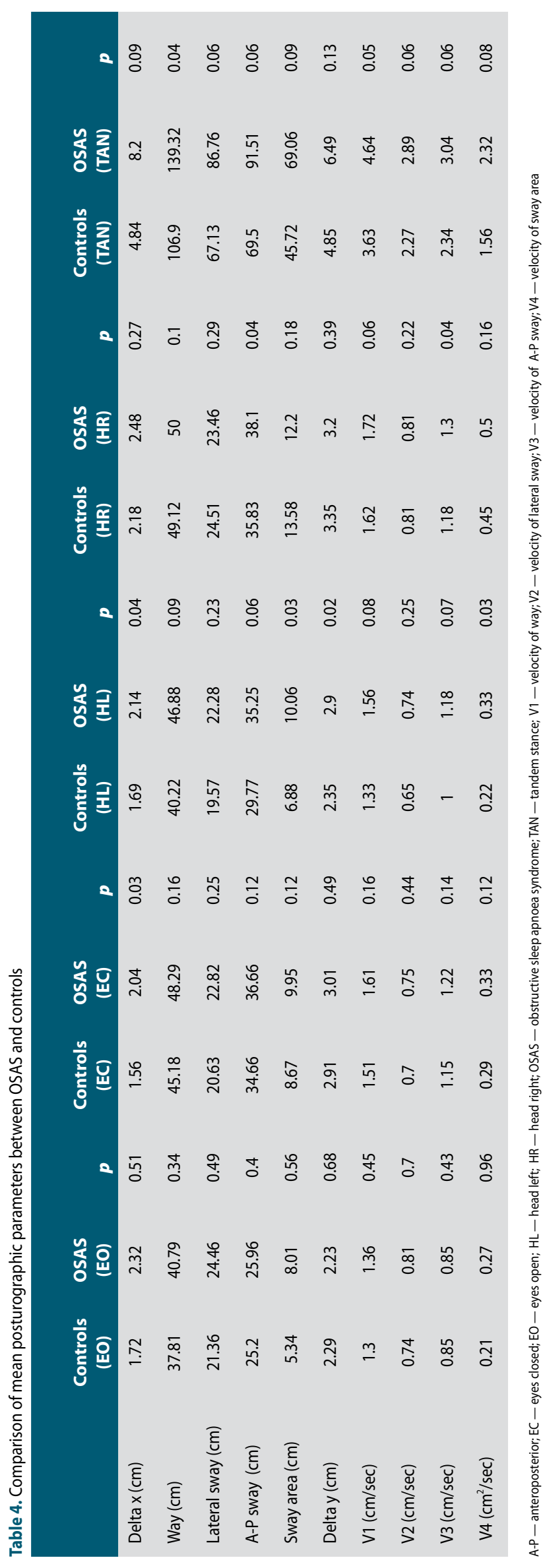

levels [23]. Balance can change depending on the time of day. It depends on two variables during the day: cyclic diurnal variation and prolonged wakefulness [22, 25]. Bougard et al. reported that postural control shows diurnal fluctuations and is better in the evening. However, they did their work only in 19 healthy controls [12]. Degache et al. used SPG and reported that nocturnal respiratory disturbances affect postural stability during the day. In addition, they noted that postural stability was especially related to both impaired sleep quality and hypoxemia. However, in the study by Degache et al., SPG was performed in the late afternoon, after the patient had been awake for several hours [16]. In the late afternoon, sleepiness is greater and patient attentiveness may be lower than during the morning.

We performed the SPG study of all patients between $7 \mathrm{am}$ and 8am. Our study showed that postural balance is affected in OSAS even in the very early morning when both attention and alertness would be expected to be at their highest. Almost all the sway parameters in EO, and some in EC and HL, conditions worsened as $\mathrm{O}_{2}$ saturation decreased. Furthermore, all sway parameters in EO, and some in $\mathrm{HL}$, conditions worsened as the nPLM increased. To date, no study has evaluated the relationship between the nPLM and postural balance. To the best of our knowledge, our study is the first to address this relation. All the data suggests that as the quality of sleep worsens, postural balance is affected more.

Studies have shown that the muscle relaxation reflex is very important in maintaining both postural stability and posture in humans [26]. It is thought that hypoxemia, which occurs during the night in OSAS cases, directly affects postural stability by changing muscle spindle reactivity [15]. This theory is supported by a change in sensorimotor stability observed in patients with respiratory or circulatory failure [27]. Alessandrini et al. reported that continuous positive airway pressure (CPAP) treatment for 12 months can improve the postural parameters of SPG in OSAS patients [28].

Our work has several limitations. Although patients with known vestibulopathy were not included in the study, there were no investigations evaluating the detailed vestibular function before enrollment. Patients were not screened for any attention deficits. The OSAS and control groups were not gender- or BMI-matched since we enrolled successive possible OSAS cases rather than healthy controls. Finally, we performed tests in the same order, from easy to difficult, in each subject only once. Therefore, we assume we minimised the practice effect.

\section{Conclusions}

Postural balance in OSAS patients is affected in relation to the severity of the disease, even early in the day. This impairment may be associated with decreased attention due to impaired sleep quality, sleep fragmentation, low oxygen saturation, and increased daytime sleepiness in OSAS. 
Table 5. Factors that affect postural control in patients with OSAS

\begin{tabular}{|c|c|c|c|c|c|c|c|}
\hline \multirow[t]{2}{*}{ Variables } & \multirow[t]{2}{*}{$\boldsymbol{\beta}$} & \multirow[t]{2}{*}{ SE } & \multirow[t]{2}{*}{ Wald } & \multirow[t]{2}{*}{$\mathbf{p}$} & \multirow[t]{2}{*}{ OR } & \multicolumn{2}{|c|}{$95 \% \mathrm{Cl}$} \\
\hline & & & & & & Min & Max \\
\hline EC-delta $x$ & 1.467 & 0.536 & 7.486 & 0.006 & 4.337 & 1.516 & 12.408 \\
\hline HL-way & 0.027 & 0.044 & 0.381 & 0.537 & 1.028 & 0.942 & 1.121 \\
\hline HL-V4 & 0.925 & 1.091 & 0.718 & 0.397 & 2.525 & 0.297 & $2 ., 412$ \\
\hline HR-V1 & 0.614 & 1.022 & 0.361 & 0.548 & 1.848 & 0.249 & 1.701 \\
\hline Neck circumference & 0.553 & 0.173 & 10.263 & 0.001 & 1.738 & 1.239 & 2.437 \\
\hline N2 & 0.119 & 0.050 & 5.604 & 0.018 & 1.127 & 1.021 & 1.243 \\
\hline
\end{tabular}

$\mathrm{Cl}$ - confidence interval; $\mathrm{EC}$ - eyes closed; $\mathrm{HL}$ - head left; $\mathrm{HR}$ — head right; $\mathrm{OR}$ - odds ratio; $\mathrm{SE}$ - standard error; $\mathrm{V} 1$ - way velocity; $\mathrm{V} 4$ - velocity of sway area

Since postural instability can lead to daytime accidents and injuries, OSAS treatment and postural stability may also afford protection by conferring the aforementioned benefits to patients with OSAS.

Conflict of interest: The authors declare no conflict of interest. Financial support: None

Acknowledgements: The authors would like to thank Ilker Unal, PhD, from the Department of Biostatistics of Cukurova University School of Medicine, for the statistical analyses.

Ethical approval: Cukurova University School of Medicine Ethics Committee approved the study protocol (protocol number: 66-2017.07.07_50).

Informed consent: Informed consent was obtained from all participants included in the study.

\section{References}

1. Spicuzza L, Caruso D, Di Maria G. Obstructive sleep apnoea syndrome and its management. Ther Adv Chronic Dis. 2015; 6(5): 273-285, doi: 10.1177/2040622315590318, indexed in Pubmed: 26336596.

2. Heinzer R, Vat $\mathrm{S}$, Marques-Vidal $\mathrm{P}$, et al. Prevalence of sleep-disordered breathing in the general population: the HypnoLaus study. Lancet Respir Med. 2015; 3(4): 310-318, doi: 10.1016/S22132600(15)00043-0, indexed in Pubmed: 25682233.

3. Peppard PE, Young T, Barnet JH, et al. Increased prevalence of sleep-disordered breathing in adults. Am J Epidemiol. 2013; 177(9): 1006 1014, doi: 10.1093/aje/kws342, indexed in Pubmed: 2358958.

4. Archbold KH, Borghesani PR, Mahurin RK, et al. Neural activation patterns during working memory tasks and OSA disease severity: preliminary findings. J Clin Sleep Med. 2009; 5(1): 21-27, indexed in Pubmed: 19317377.

5. Iber C. The AASM Manual for the Scoring of Sleep and Associated Events: Rules, Terminology and Technical Specifications 1st ed. : Wectchester, Illınois: American Academy of Sleep Medicine. ; 2007.

6. Dawson D, Reid K. Fatigue, alcohol and performance impairment. Nature. 1997; 388(6639): 235, doi: 10.1038/40775, indexed in Pubmed: 9230429.

7. Redfern MS, Yardley L, Bronstein AM. Visual influences on balance. J Anxiety Disord. 2001; 15(1-2): 81-94, doi: 10.1016/s08876185(00)00043-8, indexed in Pubmed: 11388359.
8. Morad Y, Azaria B, Avni I, et al. Posturography as an indicator of fatigue due to sleep deprivation. Aviat Space Environ Med. 2007; 78(9): 859-863, indexed in Pubmed: 17891895.

9. Bougard C, Davenne D. Morning/Evening differences in somatosensory inputs for postural control. Biomed Res Int. 2014; 2014: 287436, doi: 10.1155/2014/287436, indexed in Pubmed: 25210709.

10. Czisch M, Wehrle R, Harsay HA, et al. The effects of total sleep deprivation on cerebral responses to cognitive performance. Neuropsychopharmacology. 2001; 25(5 Suppl): S68-S73, doi: 10.1016/ S0893-133X(01)00325-6, indexed in Pubmed: 11682277.

11. Quarck G, Ventre J, Etard 0 , et al. Total sleep deprivation can increase vestibulo-ocular responses. J Sleep Res. 2006; 15(4): 369-375, doi: 10.1111/j.1365-2869.2006.00550.x, indexed in Pubmed: 17118093.

12. Vališ $M$, Dršata J, Kalfeřt $D$, et al. Computerized static posturography in Neurology. Central European J of Med. 2012; 7(3): 317-22.

13. Periodic limb movement disorder. In: The International Classification of Sleep Disorders, Revised Diagnostic and Coding Manual 2rd ed. Westchester, Illinois: American Academy of Sleep Medicine, 2005; pp 65-8.

14. Johns MW. A new method for measuring daytime sleepiness: the Epworth sleepiness scale. Sleep. 1991; 14(6): 540-545, doi: 10.1093/sleep/14.6.540, indexed in Pubmed: 1798888.

15. Izci B, Ardic S, Firat H, et al. Reliability and validity studies of the Turkish version of the Epworth Sleepiness Scale. Sleep Breath. 2008; 12(2): 161-168, doi: 10.1007/s11325-007-0145-7, indexed in Pubmed: 17922157.

16. Degache F, Goy $Y$, Vat S, et al. Sleep-disordered breathing and daytime postural stability. Thorax. 2016; 71(6): 543-548, doi: 10.1136/thoraxjnl-2015-207490, indexed in Pubmed: 26892395.

17. Nardone A, Tarantola J, Giordano A, et al. Fatigue effects on body balance. Electroencephalogr Clin Neurophysiol. 1997; 105(4): 309 320, doi: 10.1016/s0924-980x(97)00040-4, indexed in Pubmed: 9284239.

18. Howcroft J, Lemaire ED, Kofman J, et al. Elderly fall risk prediction using static posturography. PLoS One. 2017; 12(2): e0172398, doi: 10.1371/journal.pone.0172398, indexed in Pubmed: 28222191.

19. Kayabasi S, Iriz A, Cayonu M, et al. Vestibular functions were found to be impaired in patients with moderate-to-severe obstructive sleep apnea. Laryngoscope. 2015; 125(5): 1244-1248, doi: 10.1002/ lary.25021, indexed in Pubmed: 25388224.

20. Gallina S, Dispenza F, Kulamarva G, et al. Obstructive sleep apnoea syndrome (OSAS): effects on the vestibular system. Acta Otorhinolaryngol Ital. 2010; 30(6): 281-284, indexed in Pubmed: 21808447. 
21. Avni N, Avni I, Barenboim E, et al. Brief posturographic test as an indicator of fatigue. Psychiatry Clin Neurosci. 2006; 60(3): 340346, doi: 10.1111/j.1440-1819.2006.01511.x, indexed in Pubmed: 16732751.

22. Gribble PA, Hertel J. Changes in postural control during a 48-hr. sleep deprivation period. Percept Mot Skills. 2004; 99(3 Pt 1): 1035-1045, doi: 10.2466/pms.99.3.1035-1045, indexed in Pubmed: 15648505.

23. Liu Y, Higuchi S, Motohashi Y. Changes in postural sway during a period of sustained wakefulness in male adults. Occup Med (Lond). 2001; 51(8): 490-495, doi: 10.1093/occmed/51.8.490, indexed in Pubmed: 11741080.

24. Nakano T, Araki K, Michimori A, et al. Nineteen-hour variation of postural sway, alertness and rectal temperature during sleep deprivation. Psychiatry Clin Neurosci. 2001; 55(3): 277-278, doi: 10.1046/j.1440-1819.2001.00858.x, indexed in Pubmed: 11422874.
25. Haeggstrom E, Forsman P, Wallin A, et al. Evaluating sleepiness using force platform posturography. IEEE Trans Biomed Eng. 2006; 53(8): 1578-1585, doi: 10.1109/TBME.2006.878069, indexed in Pubmed: 16916092.

26. Loram ID, Maganaris CN, Lakie M. Paradoxical muscle movement during postural control. Med Sci Sports Exerc. 2009; 41(1): 198204, doi: 10.1249/MSS.0b013e318183c0ed, indexed in Pubmed: 19092688.

27. Delliaux S, Jammes Y. Effects of hypoxia on muscle response to tendon vibration in humans. Muscle Nerve. 2006; 34(6): 754-761, doi: 10.1002/mus.20633, indexed in Pubmed: 16941658.

28. Alessandrini M, Liguori C, Viziano A, et al. Postural and vestibular changes related to CPAP treatment in moderate-to-severe OSA patients: a 12-month longitudinal study. Sleep Breath. 2019; 23(2): 665-672, doi: 10.1007/s11325-018-1754-z, indexed in Pubmed: 30456739. 